\title{
BOS Vessel Vibration Measurement for Foam Level Detection
}

\author{
Mats BRÄMMING ${ }^{1,5)}$ Stuart MILLMAN, ${ }^{2)}$ Aart OVERBOSCH${ }^{3)}$ Abha KAPILASHRAMI, ${ }^{3)}$ Donald MALMBERG ${ }^{4)}$ \\ and Bo BJÖRKMAN ${ }^{51}$
}

1) SSAB EMEA, SE-971 88 Luleå, Sweden. E-mail: mats.bramming@ssab.com Technology Centre, Middlesbrough, Cleveland TS6 6US, United Kingdom

2) Tata Steel Research, D \& T, Teesside Technology Centre, 1970 CA IJmuiden, The Netherlands.

4) Process Metallurgy Department, Swerea/ MEFOS AB, SE97125 Luleå, Sweden.

5) Division of Extractive Metallurgy, Luleå University of Technology, SE-971 87 Luleå, Sweden.

(Received on July 12, 2010; accepted on September 14, 2010)

\begin{abstract}
In the BOS process liquid slag together with dispersed metal droplets, solid particles and process gases form an expanding foam. Certain process conditions may lead to excessive foam growth, forcing foam out through the vessel mouth, an event commonly known as 'slopping'. Slopping results in loss of valuable metal, equipment damage and lost production time. In the early 1980s a system for foam level and slopping control was installed at SSAB's steel plant in Luleå, a system based on the correlation between BOS vessel vibration in a narrow low frequency band and foam development. The technique, in this case with an accelerometer mounted on the trunnion bearing housing, soon showed its usefulness, for example when adapting existing lance patterns to a change in oxygen lance design from a 3-hole to a 4-hole nozzle. Estimating the actual foam height in the BOS vessel was of great importance in the recently completed RFCS funded research project "IMPHOS" (Improving Phosphorus Refining). Based on the earlier positive experiences, it was decided to further develop the vessel vibration measurement technique. Trials on an industrial size BOS vessel type LD/LBE have been carried out, this time with a tri-axial accelerometer mounted on the vessel trunnion. FFT spectrum analysis has been used in order to find the frequency band with best correlation to the foam level development. The results show that there is a correlation between vessel vibration and foam height that can be used for dynamic foam level and slopping control.
\end{abstract}

KEY WORDS: BOS; slag formation; foaming; foam level; slopping; vessel vibration.

\section{Introduction}

When converting hot metal to crude steel in a top blown Basic Oxygen Steelmaking (or BOS) process such as in the LD vessel, a slag foam (i.e. a gas-liquid-solid mixture) is formed. This foam consists of liquid slag products, dispersed metal droplets, process gases and 'second phase particles' (e.g. solid flux particles). It is generally accepted that the foam height is dependent on the viscosity and density of the liquid slag phase, surface tension between phases and, perhaps most important, the fraction of second phase particles. $^{1)}$

Early formation of a liquid slag phase is of great importance in the BOS process because optimum conditions for phosphorus refining require a large initial liquid slag volume and low metal bath temperature. However, certain process circumstances can lead to excessive volume growth of foam which cannot be contained within the vessel. This event, when the foam is forced out through the vessel mouth, is known as 'slopping' and it results in equipment damage, decreased metallic yield and lost production time. The yield losses could be substantial as the foam may contain well over $50 \%$ metallic.

The recently completed EU/RFCS supported project IMPHOS ("Improving Phosphorus Refining") was aiming to improve current BOS phosphorus refining strategies by introducing additional dynamic aspects into the control scheme, including enhanced slag formation practices and advanced lance control routines.

An important part of this project was estimating the actual foam level in the BOS vessel. The most common method today for controlling the foam level is the 'sonicmeter', where a microphone, placed in the lower stack ${ }^{2,3)}$ or close to the vessel mouth, ${ }^{4,5)}$ is used to monitor process noise, mainly created by the oxygen jet. As the foam is an acoustical insulator, the measured noise level decreases with increasing foam height. Other methods utilize oxygen lance vibration, ${ }^{2,6)}$ radio waves, ${ }^{5,7)}$ micro waves ${ }^{8,9}$ or radar. $^{10)}$ Finally, some form of indirect foam level control can be based on off-gas data. ${ }^{11,12)}$

Of the five BOS plants involved in the project, four are equipped with sonic-meter systems. However, because such systems require continuous maintenance and the fact that usable sonic readings are not obtained until 4 to $5 \mathrm{~min}$ into the blow, the project was seeking a reliable low maintenance technique which can monitor foam height from the very start to the very end of the blow, not as a substitution but as a valuable complement to the sonic-meter system.

Based on earlier experiences in the 1980s at SSAB EMEA's steel plant in Luleå, operating two BOS vessels of type $\mathrm{LD} / \mathrm{LBE}$, it was decided to carry out a deeper investigation of the method of BOS vessel vibration meas- 
urement for improved foam level estimation and slopping control. Unfortunately, due to the lack of technical documentation, all work to find a suitable sensor type and optimal placement had to start from scratch. This was not altogether negative, as there are sensor types available on the market today other than just the standard accelerometer.

\section{Theory}

In the mid-1970s Kawasaki Steel Co. carried out some fundamental work on oxygen lance vibration and vessel vibration monitoring for foam level control in the BOS vessel. For both methods, the same basic theory on the correlation between structural vibrations and foam height was applied $^{6)}$ :

- a transfer of kinetic energy from the foam to the mechanical structure for which the vibration is measured and where the amount of transferred energy, in principal, is proportional to the contact area.

This, mainly horizontal transfer of energy at the foam-tostructure interface, results in excitation of a vibration spectrum propagating through the mechanical structure.

However, the mechanical structure will act as a vibration isolator, a kind of mechanical filter. The principal vibration isolation, or vibration filter characteristics of a mechanical system, known as the "transmissibility curve"13) is illustrated in Fig. 1, in the case of a natural frequency, $f_{\mathrm{n}}$, at $7 \mathrm{~Hz}$.

The transmissibility, $T$, is the ratio between output and input vibration respectively. Two regions are recognized; the amplification region $(T>1)$ and, the isolation region $(T<1)$. From the diagram it can be seen that vibrations with a frequency close to the systems' natural frequency will be amplified, while vibrations with higher frequencies, in this case above $\sim 10 \mathrm{~Hz}$, will be progressively dampened.

When studying the lance vibration phenomena ${ }^{6}$ it was found that the vibration magnitude anywhere in the frequency spectrum increased with the actual foam height, with the best correlation between vibration level and foam height being close to the lance natural frequency $(\sim 0.4 \mathrm{~Hz})$. In this case the natural frequency is utilized to amplify the vibration signal.

However, when using vessel vibration for foam height estimation, utilizing the natural frequency as an amplifier should be avoided. The reason is that the vessel vibration frequency spectrum is the sum of several individual spectra, each a kind of a fingerprint of a specific process phenomenon. It would be quite difficult, if not impossible, to analyse the vibration signal in order to distinguish the foaming process from any other basic BOS process phenomenon.

\section{Experimental}

\subsection{Slopping Registration}

A major reason for developing methods and systems for slag formation and foam level control is the prevention of slopping and therefore, it is very helpful to have some means of recording and grading slopping events. A common method of recording slopping is image analysis utilizing surveillance cameras that cover either the area underneath the vessel $^{5)}$ or the converter mouth. ${ }^{14)}$ The former of

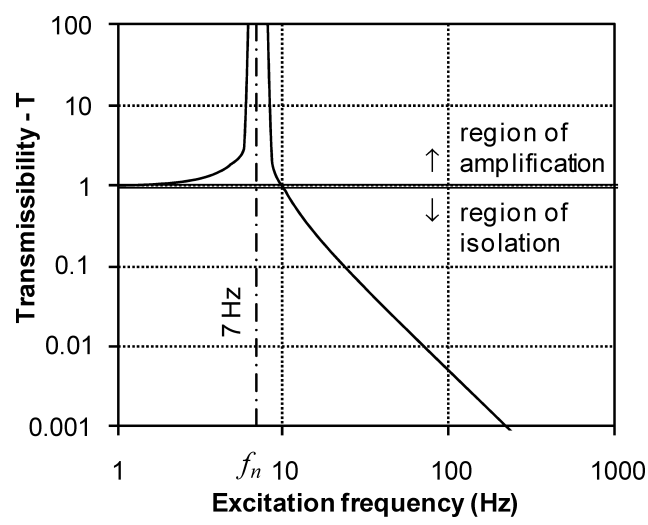

Fig. 1. The transmissibility curve for a rigid body with its natural frequency, $f_{\mathrm{n}}$, at $7 \mathrm{~Hz} .^{13)}$

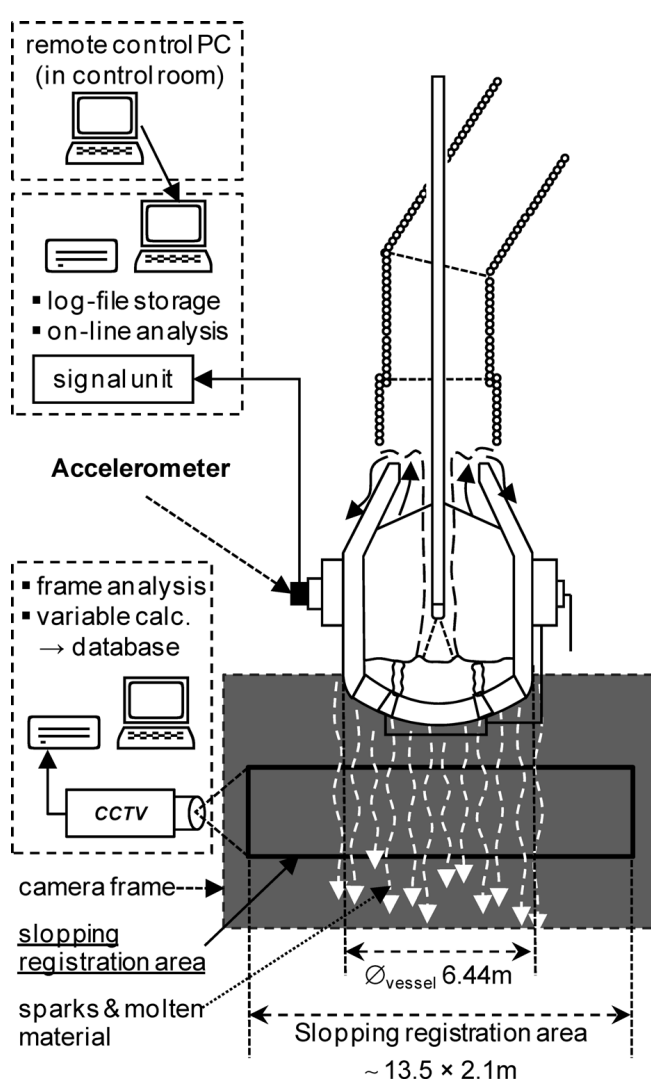

Fig. 2. Schematic description of set-up for BOS vessel slopping registration and for vessel trunnion vibration measurement.

these methods has recently been adopted at both BOS vessels at Luleå. The set-up and function of this system is illustrated in Fig. 2. This figure also describes the set-up for BOS vessel trunnion vibration measurement (see next section).

The slopping registration system downloads pictures from the CCTV at a rate of 25 frames per second. Each individual frame is scanned within a designated 'slopping registration area' (see drawn square below the vessel in Fig. 2) with a width about twice that of the vessel, and the sum of light pixels above a pre-set threshold is counted (eliminating "contamination" by light sources such as indoor lighting). This count is then used to calculate a 1-s average 'slopping value', being the percentage of light pixels to the total number of pixels in the designated slopping registra- 


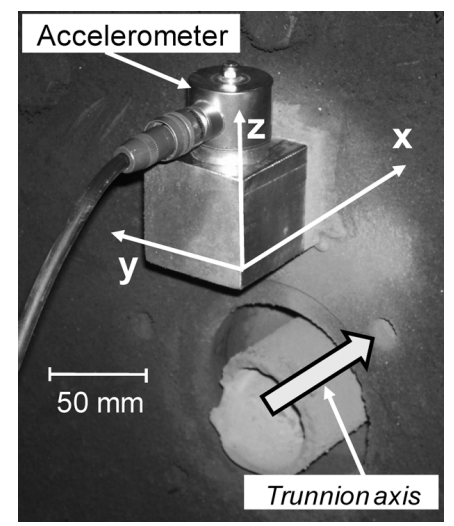

Fig. 3. Accelerometer mounting on trunnion.

tion area of the CCTV frame.

The slopping value is stored (as a 2-s average value) in the data base for a period of up to two weeks. For long-term data storage a 'slopping index' $(\Sigma \%)$ for each heat is created by accumulating the 1-s slopping value over the complete blow. An average slopping value for each individual blowing minute (from 1st to 20th) is also calculated and stored "indefinitely".

At this point it must be emphasized that the slopping value is not a quantitative measure of the intensity of foaming inside the steelmaking vessel, rather a qualitative measure of the level of excess foaming and only in the event of foam being forced out of the vessel.

\subsection{Vessel Vibration Measurements}

\subsubsection{Measurement Technique}

Two principally different sensors were tested; 'laser doppler vibrometer' and 'triaxial piezoelectric charge accelerometer'. It was soon realized, that the most practical method was to use an accelerometer. The sensor for BOS vessel vibration measurement that was finally selected was a triaxial accelerometer with a range of $0.5-5000 \mathrm{~Hz}$ and a sensitivity of $10.2 \mathrm{mV} /\left(\mathrm{m} / \mathrm{s}^{2}\right)$.

The most useful placement of the accelerometer was found to be on the BOS vessel trunnion system. Tests were carried out with accelerometers mounted both on the end of the trunnion pin and on the bearing housing. The results showed that the best vibration signal is obtained with a direct trunnion mounting as shown in Fig. 3 .

\subsubsection{Logging and On-line Analysis}

The accelerometer was connected to a signal amplifying and logging unit. This unit was in turn, connected to a laptop PC in which the log-files were automatically stored at the end of each measurement period.

Specially designed logging software was used for on-line frequency spectrum analysis by FFT $^{13)}$ (Fast Fourier Transform) and for calculation of the RMS ${ }^{13}$ ) (Root Mean Square) amplitude of a accelerometer signal within a given frequency band.

\subsubsection{Measurement Set-up}

A schematic description of the BOS vessel trunnion vibration measurement set-up was given in Fig. 2. The accelerometer was mounted on a square piece of solid steel
Table 1. Process data for BOS vessel vibration trials $(\mathrm{BF}=$ blast furnace, E.O.B. $=$ end of blow, $\mathrm{kg} / \mathrm{t} . \mathrm{liq}=\mathrm{kg}$ per tonne tapped liquid steel).

\begin{tabular}{|c|c|c|}
\hline Process parameter & unit & Average data \\
\hline Heat size & tonne & 112.9 \\
\hline \multicolumn{3}{|l|}{ Hot metal: } \\
\hline - charge & $\mathrm{kg} / \mathrm{t}$.liq & 890 \\
\hline - Si content & $\%$ & 0.36 \\
\hline - $\mathrm{P}$ content & $\%$ & 0.036 \\
\hline \multicolumn{3}{|l|}{ Scrap/coolants: } \\
\hline - cold iron & $\mathrm{kg} / \mathrm{t}$.liq & 40 \\
\hline - slab \& plate & $\mathrm{kg} / \mathrm{t}$.liq & 57 \\
\hline - purchase & $\mathrm{kg} / \mathrm{t}$.liq & 36 \\
\hline - sculls & $\mathrm{kg} / \mathrm{t}$.liq & 38 \\
\hline - BF pellet & $\mathrm{kg} / \mathrm{t}$.liq & 11 \\
\hline \multicolumn{3}{|l|}{ Fluxes: } \\
\hline - burnt lime & $\mathrm{kg} / \mathrm{t}$.liq & 31 \\
\hline - dolomitic lime & $\mathrm{kg} / \mathrm{t}$.liq & 24 \\
\hline Slopping index & $\Sigma \%$ & 1,280 \\
\hline \multicolumn{3}{|l|}{ E.O.B.: } \\
\hline - $\mathrm{C}$ content & $\%$ & 0.053 \\
\hline - temperature & ${ }^{\circ} \mathrm{C}$ & 1,688 \\
\hline \multicolumn{3}{|l|}{ Slag: } \\
\hline$-\mathrm{Fe}_{\mathrm{tot}}$ & $\%$ & 16.7 \\
\hline$-\mathrm{CaO} / \mathrm{SiO}_{2}$ & - & 4.7 \\
\hline$-\mathrm{MgO}$ & $\%$ & 12.3 \\
\hline
\end{tabular}

welded onto the end of the trunnion on the drive-side of BOS vessel LD\#1 in such a way that the sensor $x$-direction was along the trunnion axis, as shown in Fig. 3.

\subsection{Trial Description}

\subsubsection{Procedures and Process Conditions}

The trunnion vibration trials were divided into two parts. During the first half there was no modification of process settings, while the second half was conducted with a new set of lance patterns and with tight control of scrap quality. Some average process data for the total trial series are listed in Table 1.

\subsubsection{Signal Logging and Process Data Collection}

Logging of the vibration signal commenced immediately after the vessel came to the upright position after charging and then terminated prior to tapping. The signal sampling frequency was kept constant at $2.5 \mathrm{kHz}$.

Process data collected were specific heat data as well as continuous logged data on 2-s level, such as decarburization rate, flux additions, lance level and registered slopping values.

\section{Vibration Signal Analysis}

Recorded vibration signals were analysed using specially designed MATLAB software, in which the analysis was divided into two parts;

(1) Frequency spectrum analysis by FFT; for the determination of the overall vibration behaviour, including finding the system natural frequencies, and

(2) RMS amplitude calculation; to study variations in vibration amplitude level through the course of the blow for a number of selected frequency bands.

In selecting the frequency bands for which the RMS amplitude should be calculated, there are two principal approaches; 'constant band width' or 'constant percentage 
Table 2. Lower and upper frequency limits, and mid-frequencies for some standardized $1 / 3$-octave band filters.

\begin{tabular}{|c|c|c|c|}
\hline Band & $\boldsymbol{f}_{\boldsymbol{l}}, \mathbf{H z}$ & $\boldsymbol{f}_{\boldsymbol{u}}, \mathbf{H z}$ & $\boldsymbol{f}_{\boldsymbol{0}}, \mathbf{H z}$ \\
\hline 7 & 4.47 & 5.62 & 5 \\
\hline 8 & 5.62 & 7.08 & 6.3 \\
\hline 9 & 7.08 & 8.91 & 8 \\
\hline 10 & 8.91 & 11.2 & 10 \\
\hline 11 & 11.2 & 14.1 & 12.5 \\
\hline 12 & 14.1 & 17.8 & 16 \\
\hline
\end{tabular}

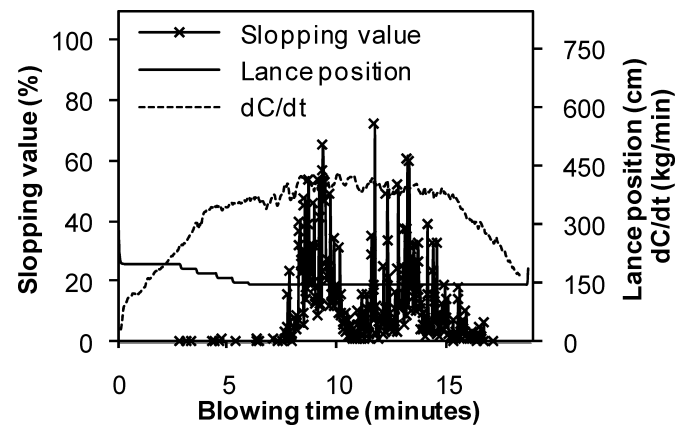

Fig. 4. Example of recorded slopping during a BOS heat $\left(\mathrm{O}_{2}\right.$ flow rate at $340 \mathrm{Nm}^{3} / \mathrm{min}$ ), data as 2 -s average values.

band width' (CPB). The former is mainly used in vibration analysis, while the latter is normally used in acoustics analysis. For CPB the band width increases with increasing mid-frequency. Commonly used CPB-filters are 'one-third (1/3-) octave filters' with standardized mid-frequencies. Table 2 lists some standardized 1/3-octave band filters, ${ }^{15}$ where $f_{1}$ is the lower frequency limit (of the band), $f_{\mathrm{u}}$ the upper frequency limit and $f_{0}$ the mid-frequency.

Analysis of the BOS vessel trunnion vibration recordings used 1/3-octave analysis for the first level of frequency analysis, while constant band width was applied for narrowing down (pinpointing).

\section{Results}

\subsection{Slopping Registration}

As mentioned earlier, it is essential to have an objective system for recording slopping events with regard to both time and severity. The installed image analysis system has proved to be a very useful tool in this respect. An example of a slopping record is shown in Fig. 4.

\subsection{Frequency Analysis}

\subsubsection{Total Blowing Period Frequency Spectrum}

The initial vibration signal analysis work was aimed at indicating where in the frequency spectrum to look for a strong correlation with a plausible foam level. This was achieved by establishing the total frequency spectrum covering a number of complete blowing periods, which is accomplished by setting the FFT-length equivalent to the blowing time.

In order to determine the existence of any non-process related vibration activity, it is necessary to compare the total frequency spectrum for the blowing period with the spectrum for a charged vessel prior to blowing. Such a comparison is illustrated in Fig. 5. The figure shows three sets of twin-diagrams, one set for each vessel direction $(x-$,
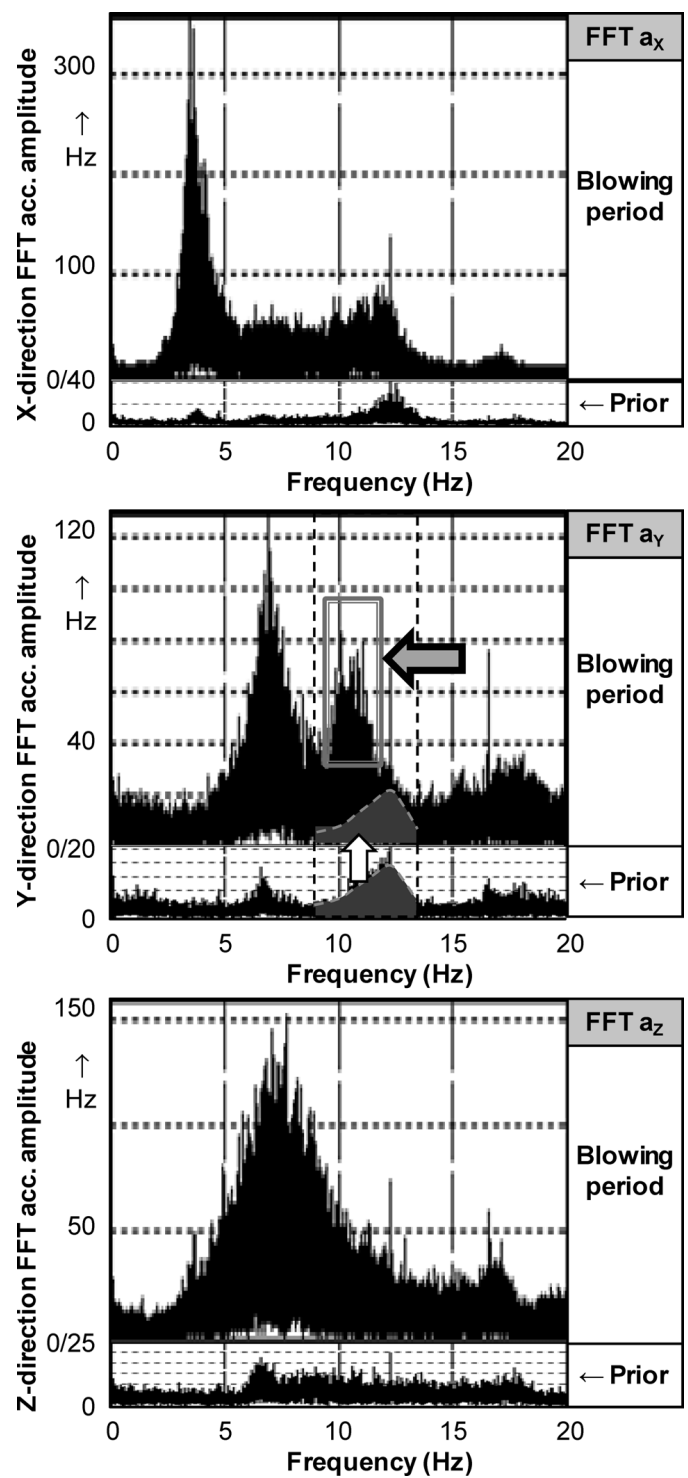

Fig. 5. Comparison of blowing period frequency spectra $0-20 \mathrm{~Hz}$ with spectra for a charged BOS vessel prior to blow.

$y$ - and $z$ - respectively), where in each set the top frequency spectrum is for the blowing period and the bottom frequency spectrum is for the period prior to blowing.

The total blowing frequency spectra shown in Fig. 5 (top diagrams) are for a BOS heat with heavy slopping. For all directions, a dissection of this heat (and several others) into $105 \mathrm{~s}$ periods shows that the total blowing period frequency spectra remain unchanged throughout the blow as far as the position of the peaks is concerned.

Studying the results of the spectrum analysis prior to blowing (bottom diagrams in Fig. 5), it can be seen that the average frequency amplitude level prior to blowing is only 10 to $20 \%$ compared with the level during the blow, indicating a minimum of movement of the vessel and its liquid content before blowing is commenced.

Common in all three directions, prior to as well as during the blowing period, are more or less distinct peaks in the lower frequency area, just below $4 \mathrm{~Hz}$ in the $x$-direction and at $7 \mathrm{~Hz}$ in the $y$-direction as well as in the $z$-direction.

Looking closer at the $9-13 \mathrm{~Hz}$ area in the BOS vessel $y$ direction (Fig. 5 centre diagrams), an interesting difference in the frequency spectra between the periods prior to and 


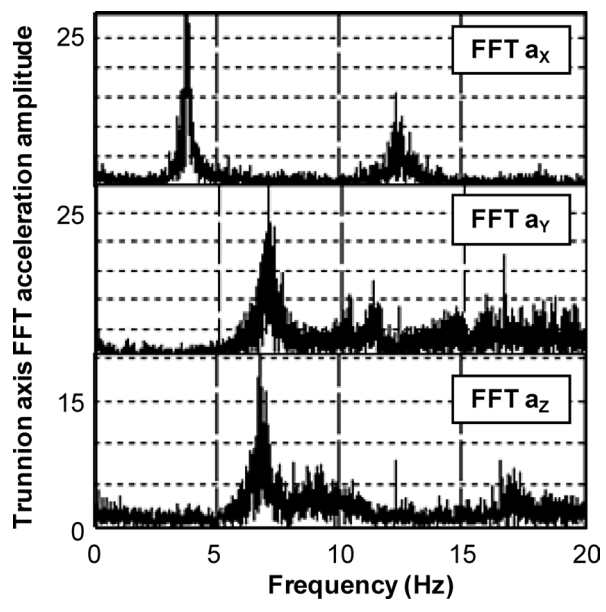

Fig. 6. Sum of frequency spectra over a series of knocks on the BOS vessel shell.

during blowing appears. During the blow the vibration amplitude is elevated considerably in a narrow area at $10-11 \mathrm{~Hz}$, an area which is quite "inactive" prior to blowing. There is some limited "activity" prior to blowing around $12 \mathrm{~Hz}$, but it remains unchanged during blowing. This last observation could be the first clue to where to find a useful correlation between BOS vessel vibration and the foam level.

\subsubsection{Resonance Investigation}

When searching for correlations between vessel trunnion vibrations and BOS process phenomena, account needs to be taken of the resonance characteristics of the vessel system. For a complex system such as the BOS converter, with a vessel suspended in the trunnion ring, natural frequencies cannot be calculated. The only way is to physically put the vessel into motion while recording the vibration signals and then study the resulting trunnion vibration frequency spectrum. This was achieved by knocking on the vessel shell using the tip of the telescopic boom from a debricking machine.

A series of intermittent taps were recorded for a charged vessel prior to blowing. Fig. 6 shows the sum of frequency spectra for a series of five distinct knocks on the vessel.

The frequency spectra in Fig. 6 indicates that the 1st order natural frequency is very close to $4 \mathrm{~Hz}$ in the $x$-direction, $7 \mathrm{~Hz}$ in the $y$-direction and just below $7 \mathrm{~Hz}$ in the $z$-direction. Any natural frequencies of higher order are not evident below $20 \mathrm{~Hz}$ except at $12 \mathrm{~Hz}$ in the $x$-direction, even though there are two smaller peaks just above $10 \mathrm{~Hz}$ in the $y$-direction and one at $17 \mathrm{~Hz}$ in the $z$-direction.

It is concluded, from the heat dissection mentioned in the Sec. 5.2.1, that there is no evident shift in resonance behaviour throughout the blow.

\subsubsection{RMS Amplitude Calculations}

An example of the result of vibration RMS amplitude calculations is shown in Fig. 7. Here the RMS values refer to vibration in the vessel $y$-direction for $1 / 3$-octave band no.s 7 to 12, where (for simplicity reasons) each plotted data point represents the average of 9 consecutive RMS values (i.e. approximately 30 -s average values).

Comparing the slopping value curve with the plotted

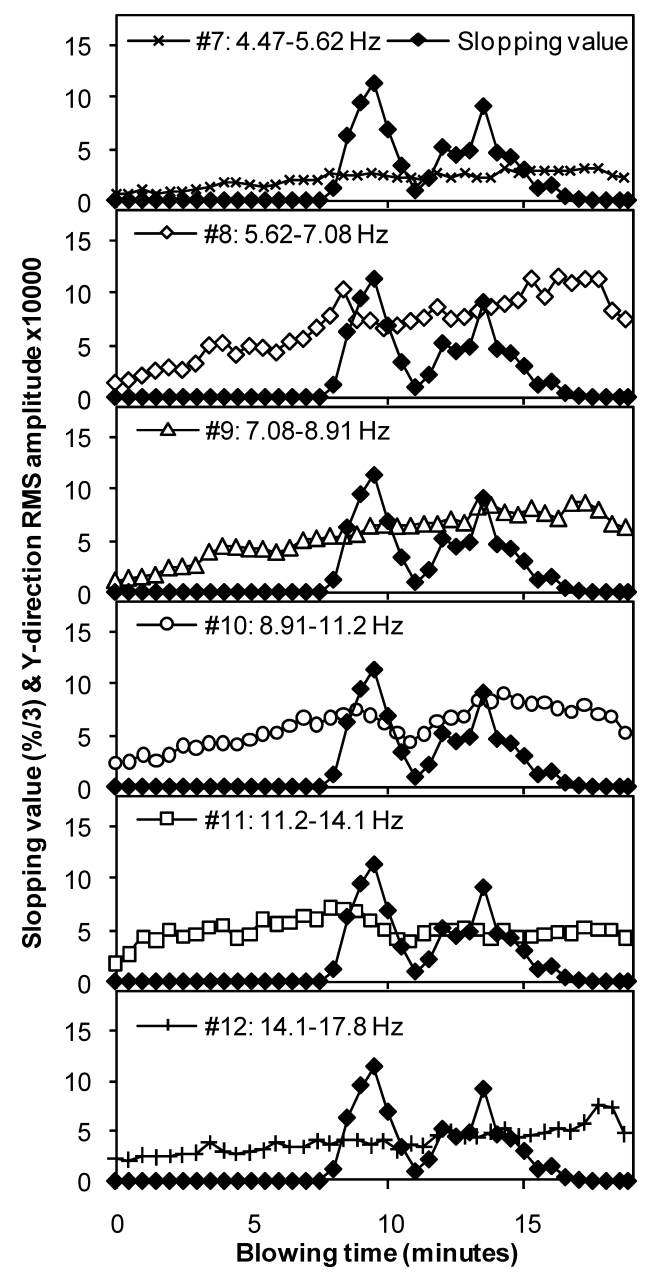

Fig. 7. RMS amplitude calculation for 1/3-octave frequency bands no.s 7 to 12 in the BOS vessel $y$-direction, together with recorded slopping values (all values as 30 -s average values).

RMS curves in Fig. 7, it appears that a frequency band with satisfactory correlation to the foam level should be found within frequency band no. 10, i.e. 8.91 to $11.2 \mathrm{~Hz}$.

\subsection{Trunnion Vibration and Foam Level}

Knowing the actual foam height inside the vessel is of course a big advantage in developing any type of dynamic foam level control system. However, in most cases the only time the absolute foam level is known is when the vessel is slopping. Hence, slopping heats were the first choice for detailed examination.

In-depth evaluation of frequency band correlations with slopping heats was carried out along the following principal path:

(1) Choosing appropriate trunnion vibration direction

(2) Determining optimum mid-frequency

(3) Determining appropriate frequency band width.

To illustrate the deduction process, a selected slopping heat (X-3288 on vessel LD\#1) will serve as an example.

\subsubsection{Choice of Trunnion Vibration Direction}

As the foam only comes in contact with the cylindrical part of the vessel, the main force acting on the wall will be in the horizontal plane, i.e. along and across the trunnion axis. This means that the investigation into a correlation 


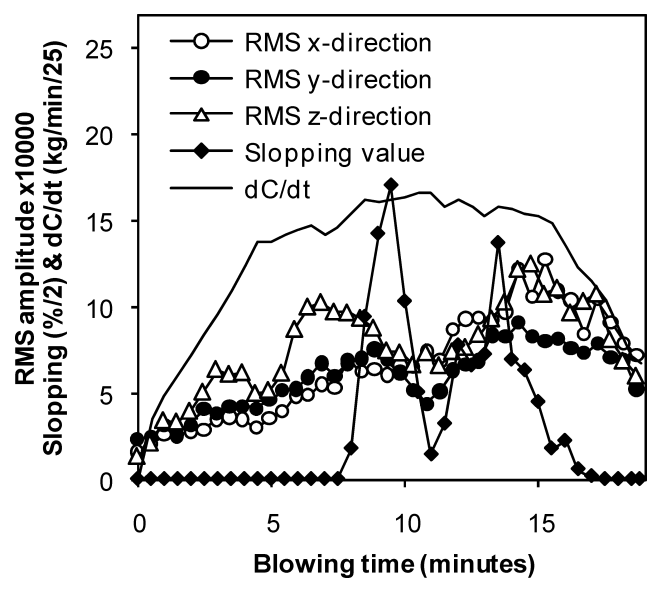

Fig. 8. RMS amplitude patterns in the $1 / 3$-octave frequency band $8.91-11.2 \mathrm{~Hz}$, together with $d C / d t$ and slopping value (30-s average values).

between vessel vibration patterns and foam level should be focused on the vessel/accelerometer $x$ - and $y$-directions.

In Fig. 8 vibration RMS amplitude values in the $x$-, $y$ and $z$-directions for the $1 / 3$-octave frequency band $8.91-11.2 \mathrm{~Hz}$ are plotted alongside decarburization rate $(d C / d t)$ and slopping value (30-s average data).

Only the $y$-direction RMS amplitude pattern shows an evident correlation with the slopping value curve, peaking and declining at the same time as the slopping value.

In the $x$-direction there is a continuous increase in amplitude until the very last part of the blow, without any noticeable drop between minutes 10 and 11 when slopping is temporarily subsiding.

The RMS amplitude pattern in the $z$-direction deviates even more from the slopping curve, especially in the first part of the blow. Hence, from the patterns shown in Fig. 8, the conclusion must be that further investigation should concentrate on BOS vessel vibration frequency analysis in the $y$-direction, i.e. in the horizontal direction perpendicular to the vessel trunnion axis.

\subsubsection{Determining Optimum Mid-frequency}

The approximate mid-frequency position for foam level estimation was determined by examining RMS patterns in the $y$-direction. Going back to Fig. 7, it is clear that the all RMS patterns except for the 1/3-octave frequency band \#10 show poor correlation with the slopping value. The latter frequency band, however, exhibits good correlation with the slopping value. Therefore it should be expected that a suitable mid-frequency for foam level estimation is to be found within the 1/3-octave band 8.91-11.2 Hz.

The next step is to carry out a constant band width analysis between 8.5 and $11.5 \mathrm{~Hz}$, divided into two parts; first with a narrow band width analysis to pinpoint the optimum mid-frequency, followed by determination of the most suitable band width. Figure 9 shows the result of a narrow band width analysis with an individual band width of $0.5 \mathrm{~Hz}$.

The top three frequency bands in Fig. 9 reach their first maximum close to, or even after the end of the second slopping peak, while the bottom frequency band in Fig. 9 decreases more or less continuously after peaking at the

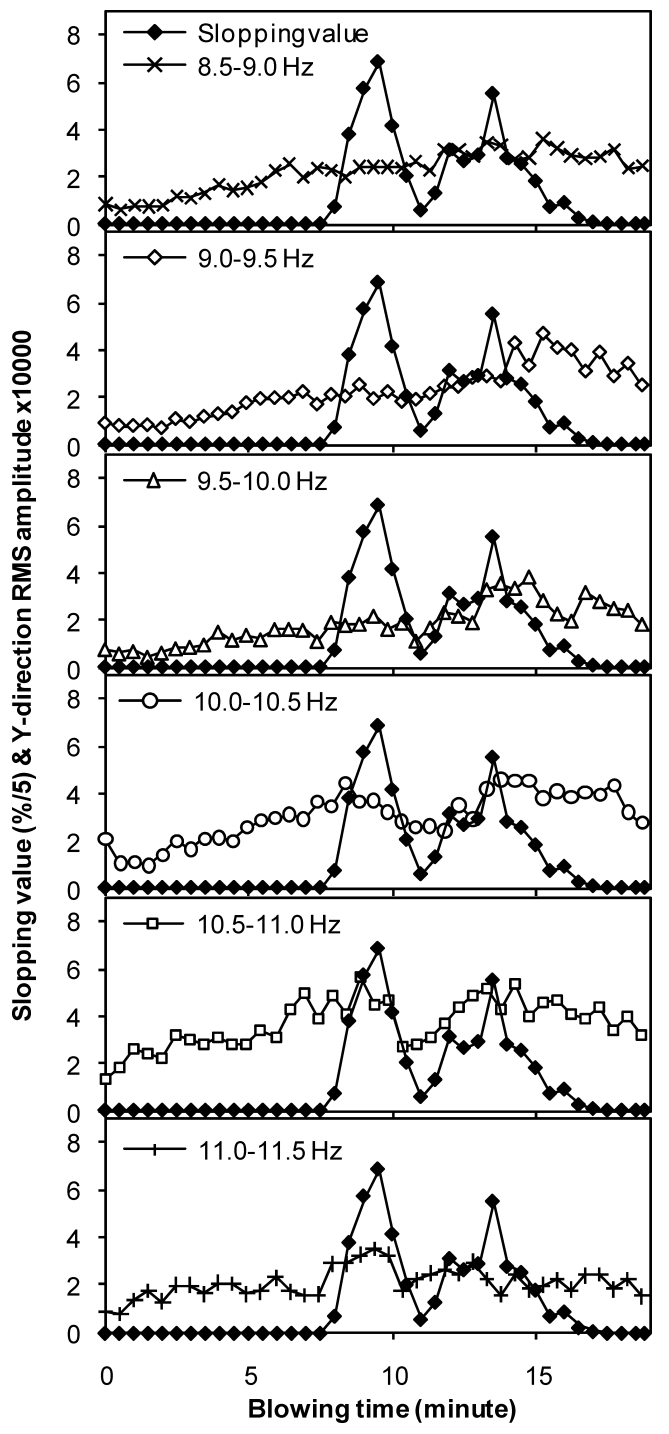

Fig. 9. RMS patterns for $0.5 \mathrm{~Hz}$ wide frequency bands from 8.5 to $11.5 \mathrm{~Hz}$ in the vessel $y$-direction, together with the slopping value.

first slopping instance. However, the two bands in between (i.e. $10-10.5$ and $10.5-11 \mathrm{~Hz}$ ) display patterns quite similar to the slopping value curve. The conclusion of this single heat analysis is that a mid-frequency between 10 and $11 \mathrm{~Hz}$, i.e. of $10.5 \mathrm{~Hz}$ should be selected.

\subsubsection{Determining Appropriate Frequency Band Width}

The final step is determination of the band width. Using a mid-frequency of $10.5 \mathrm{~Hz}$, Fig. 10 shows vibration RMS patterns calculated for band widths from 0.5 up to $5.0 \mathrm{~Hz}$ and then compared with the slopping value. A detailed examination of vessel vibration between 13 and $17 \mathrm{~min}$ when slopping is finally subsiding, shows that the optimum band width is between 1 and $2 \mathrm{~Hz}$. Within this range the progress of the vibration RMS amplitude patterns shows good correlation with the drop in slopping value, as can be seen in the top diagram in Fig. 10.

Below $1 \mathrm{~Hz}$ and above $2 \mathrm{~Hz}$ band width, the drop in vibration RMS amplitude is insignificant between 13 and $17 \mathrm{~min}$ (see bottom diagram in Fig. 10). This suggests influence of some other process phenomena, causing the excitation of vibrations below $10 \mathrm{~Hz}$ and above $11 \mathrm{~Hz}$ in the fre- 


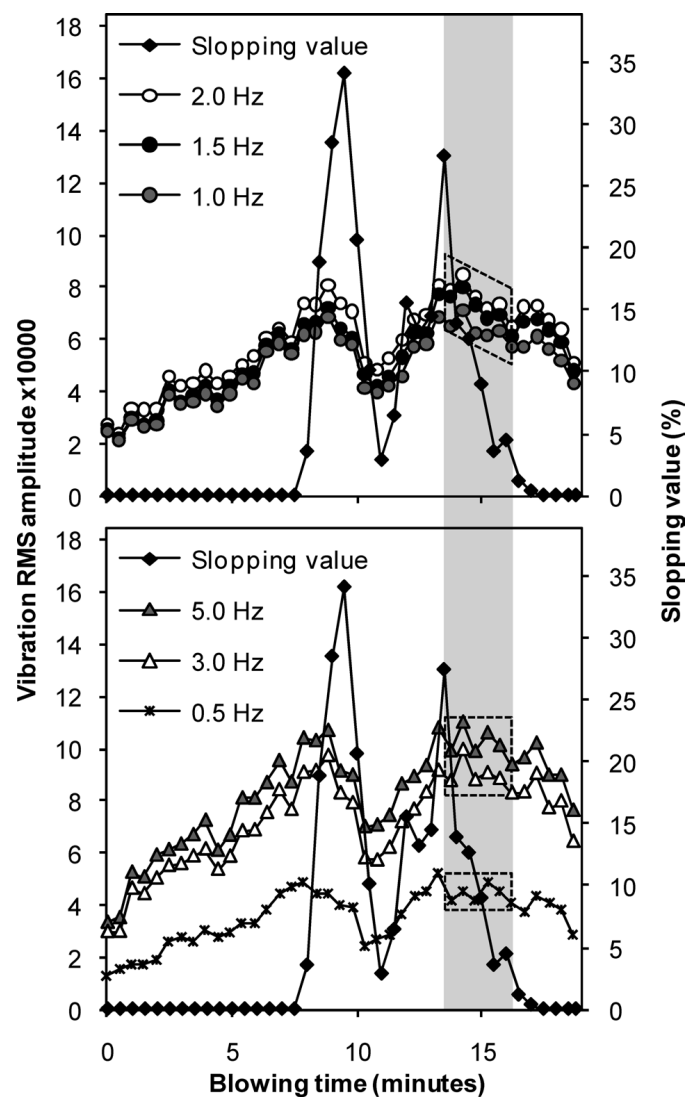

Fig. 10. Slopping and RMS vibration patterns in the BOS vessel $y$-direction for a $10.5 \mathrm{~Hz}$ mid-frequency and selected band widths. Top: 1.0, 1.5 and $2.0 \mathrm{~Hz}$. Bottom: 0.5, 3.0 and $5.0 \mathrm{~Hz}$.

quency spectrum in the later part of the blow.

\section{Discussion}

\subsection{Vessel Vibration and Foam Height}

This investigation was aimed at performing a deeper analysis into the relationship between vessel vibration and foam height in a top blown steelmaking vessel.

The documented difference in vibration RMS patterns between slopping and non-slopping heats, exemplified in Fig. 11, is typical of the entire trial series, confirming the existence of a strong connection between vessel vibration and foam height.

A single heat analysis showed that the best correlation with foam height and indication of imminent slopping was given by the vibration RMS amplitude for the frequency band $9.75-11.25 \mathrm{~Hz}$ in the vessel $y$-direction, i.e. horizontal and $90^{\circ}$ to the trunnion axis. This finding is in good agreement with the $10 \mathrm{~Hz}$ mid-frequency used when the technique was first implemented in Luleå in the 1980s.

Referring to the theory on vibration isolation illustrated in Fig. 1, it is probable that the optimum mid-frequency is dependent on the BOS vessel natural frequency, $f_{\mathrm{n}}$. This frequency is reciprocally proportional to the square root of the total mass of the system. ${ }^{13)}$ Therefore, it is expected that the optimum mid-frequency will decrease with increasing vessel mass.

In practice, the band width chosen for foam height and slopping control may need to be wider than $1-2 \mathrm{~Hz}$ in order

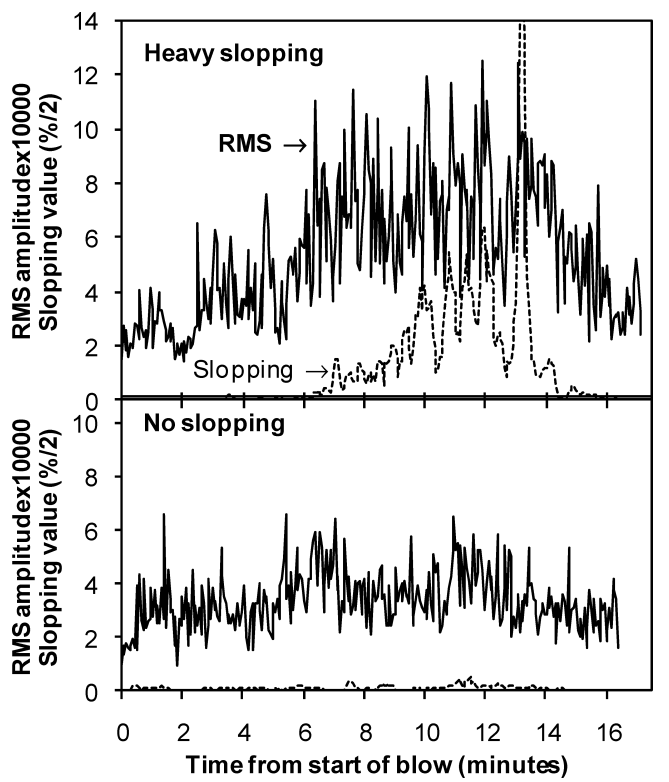

Fig. 11. Vessel vibration RMS amplitude patterns for the frequency band $9.75-11.25 \mathrm{~Hz}$ for a heavy slopping (top) and a non-slopping heat (bottom), and coinciding slopping values.

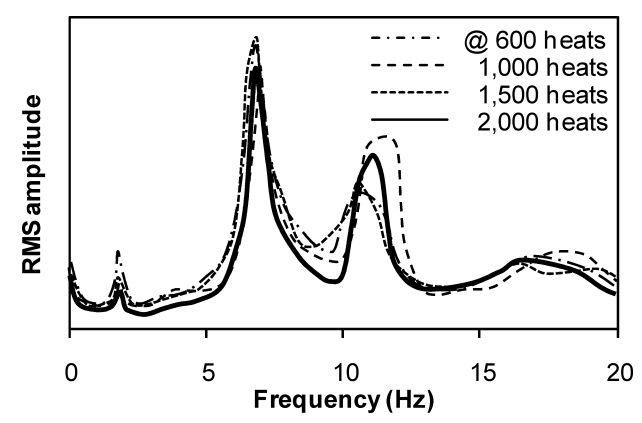

Fig. 12. Comparison of total trunnion vibration frequency spectrum over a complete blow for individual slopping heats at different points in the BOS vessel campaign.

to cover shifts in the vessel natural frequency. It has yet to be determined which parameters may cause such shifts but it is obvious that any change in the vibration filter characteristics of the BOS vessel system will have an effect on the choice of frequency band.

To detect the effects of long-term changes on the overall vessel vibration frequency spectrum, a comparison was made between slopping heats at different points in the vessel campaign. Obtained spectra plotted in Fig. 12 show no significant change in the vibration frequency spectrum except in individual heat vibration RMS amplitude levels.

Two peaks remain quite constant; one at the $7 \mathrm{~Hz}$ natural frequency $\left(f_{\mathrm{n}}\right)$ and another peak just below $2 \mathrm{~Hz}$. The latter peak most likely represents the frequency of the metallic bath standing wave caused by the impingement of the oxygen jet. ${ }^{16,17)}$

\subsection{Foam Height Estimation and Slopping Prediction}

To utilize vessel vibration for slopping prediction, it is necessary to establish a mathematical relationship between vibration RMS amplitude level and foam height.

Based on the theory adopted to explain this relationship, i.e. the transfer of kinetic energy from foam to vessel wall, 


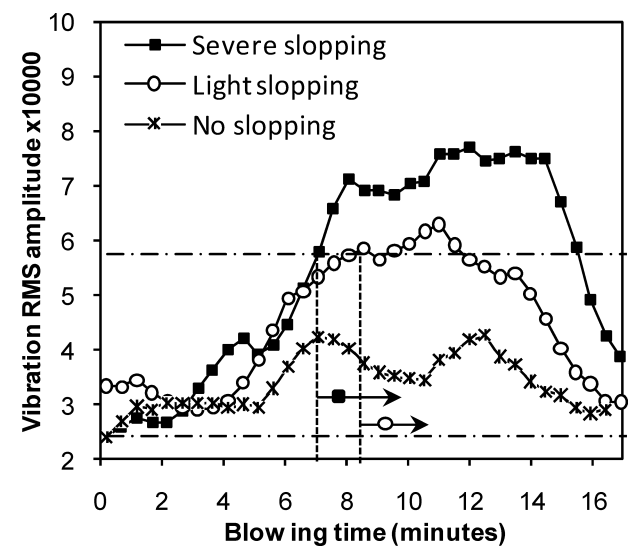

Fig. 13. Vibration RMS amplitude curves for one heavy slopping, one light slopping and one non-slopping heat, for the frequency band $9.75-11.25 \mathrm{~Hz}$ (30-s average values).

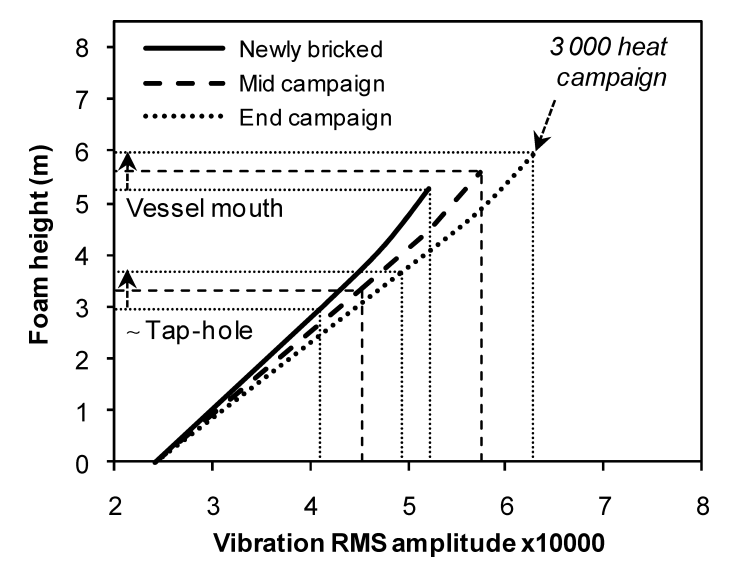

Fig. 14. Principal approach to a basic relationship between vessel vibration RMS amplitude and foam height. Line for "mid-campaign" based on Fig. 13, where all plotted curves are for heats half-way into a 3000 heat vessel campaign.

a first approximation would be a linear relationship between vibration amplitude ( $\propto$ kinetic energy transfer) and foam height ( $\propto$ foam-to-wall contact area). The quantification would then be based on the increase in vibration RMS amplitude from start of the blow to the point when the foam overflows the vessel mouth.

Vibration RMS amplitude curves for one heavy slopping, one light slopping and one non-slopping heat (all heats half-way into the vessel campaign) are plotted in Fig. 13. The time when foam starts to overflow the vessel mouth is indicated by dashed vertical lines, at about $7 \mathrm{~min}$ for the heavy slopping heat and between 8 and 9 min for the light slopping heat.

As seen in Fig. 13, slopping begins at a vibration RMS amplitude just below 0.0006. Applying a 0.00024 base line for the vibration amplitude level at start of blow, a first attempt to quantify the relationship between vibration RMS amplitude and foam height is shown in Fig. 14.

To compensate for the continuous wear of the vessel lining, the value for the vibration RMS amplitude over which slopping is expected needs to be adjusted (as shown in Fig. 14), as the ratio of contact area to foam height increases with increased vessel diameter and as the distance from bath level to vessel mouth increases with increasing bottom wear.

\section{Conclusions}

(1) During the BOS process, transfer of kinetic energy from the foaming slag to the vessel results in vibration excitation at the vessel wall. These vibrations propagate through the vessel structure, but only the lower part of the vibration frequency spectrum will travel all the way to the outer parts of the structure, as the vessel itself will act as a mechanical filter.

(2) Best correlation with foam level is obtained with the vibrations in the horizontal $y$-direction, i.e. in the vessel tilting direction. This observation is not surprising, as the forces of the foaming slag only act on the vertical part of the vessel.

(3) Most favourable and practical is to monitor vessel vibrations by placing an accelerometer on the trunnion. It should be on the drive-side, as here the trunnion is free to move.

(4) As the resonance and hence the filtering properties of the vessel mechanical structure will vary from converter to converter, so will the optimum frequency band. It will however, remain constant for an individual converter as long as no major change is made to the vessel design.

(5) The results indicate that there is a correlation between vibration and foam height that can be used for dynamic foam level and slopping control.

\section{Acknowledgements}

The authors wish to acknowledge that the experimental work and analysis presented in this article was carried out with a financial grant from the Research Fund for Coal and Steel of the European Community.

It should also be acknowledged that this publication is a part of an industrial PhD work carried out at the Division of Extractive Metallurgy, Luleå University of Technology, and linked to the PRISMA Centre for Process Integration in Steelmaking, a research centre located at Swerea MEFOS which is supported by Scandinavian mining and metallurgical industries and by VINNOVA (The Swedish Governmental Agency for Innovation Systems), SSF (The Swedish Foundation for Strategic Research) and KK-stiftelsen (The Knowledge Foundation, a research financier for Swedish institutions for higher education).

\section{REFERENCES}

1) K. Ito and R. J. Fruehan: Metall. Trans. B, 20B (1989), 515.

2) T. Kanai, A. Sakai, J. Tani, S. Yoshida and N. Matsui: Proc. of 2nd European Oxygen Steelmaking Congress, AIM, Milan, (1997), 267.

3) J. W. K. van Boggelen: Proc. of 5th European Oxygen Steelmaking Conf., Steel Inst. VDEh, Aachen, (2006), 108, CD-ROM.

4) C. Bencini and A. Poli: Proc. of 76th Steelmaking Conf., Iron and Steel Society, Warrendale, PA, (1993), 193.

5) J. Ruuska, S. Ollila, L. Bååth and K. Leiviskä: Proc. of 5th European Oxygen Steelmaking Conf., Steel Inst. VDEh, Aachen, (2006), 210, CD-ROM.

6) Y. Iida, K. Emoto, M. Ogawa, Y. Masuda, M. Onishi and H. Yamada, Trans. Iron Steel Inst. Jpn., 24 (1984), 540.

7) M. S. Millman, L. Bååth, D. Malmberg and E. Price: Proc. of 2nd Int. Congress on the Science and Technology of Steelmaking, Vol. 1, University of Wales, Swansea, (2001), 309. 
8) T. Saito, I. Tsubone, M. Azuma, H. Yamana and H. Takezoe: Tetsoto-Hagané, 76 (1990), 1978

9) D. Malmberg, P. Hahlin and E. Nilsson: ISIJ Int., 47 (2007), 533.

10) R. Bruckhaus, V. Fiedler and H. Lachmund: Rev. Metall., June (2001), 553.

11) T. Takawa, K. Katayama, K. Katohgi and T. Kuribayashi: Trans. Iron Steel Inst. Jpn., 28 (1988), 59.

12) P. G. Garnica, R. D. Morales and N. U. Rodríguez: Proc. of Metallurgical Processes for Early Twenty-First Century, The Minerals, Metals \& Materials Society, Warrendale, (1994), 631.

13) L. Beranek and I. Vér: Noise and Vibration Control Engineering,
Wiley-Interscience, John Wiley \& Sons, Inc., New York, NY, USA, (1992), ISBN 0-471-61751-2, 49-56, 430, 566.

14) C. Kattenbelt, E. Spelbos, P. Mink and B. Roffel: Steel Res., 79 (2008), No. 11, 821.

15) M. P. Norton and D. G. Karczub: Fundamentals of Noise and Vibration Analysis for Engineers 2nd edition, Cambridge University Press, Cambridge, New York, (1989), ISBN 0-521-49913-5, 264.

16) M. S. Lee and S. L. O'Rourke: Iron Steelmaker, 28 (2002), No. 9, 56.

17) M. J. Loumala, T. M. J. Fabritius and J. J. Härkki: ISIJ Int., 44 (2004), 809 